\title{
Influence of Splenectomy upon Cerebral Excitability of Rabbits
}

By

\section{Takashi Mizuno}

\author{
From the Department of Pediatrics, Faculty of Medicine, Tohoku \\ University, Sendai; Director: Prof. Ts. A r a k a wa
}

(Received for publication, August 23, 1962)

In our clinical experience, a child with akinetic epilepsy happened to be free from the fits after repeated $x$-ray irradiation upon the splenic region. Even though such a dramatic improvement would be accidental and not necessarily be related to the $x$-ray irradiation itself, it was a very impressive event for us. A possibility of the existence of a certain relationship between splenic function and cerebral excitability has been suspected since that time.

The present investigation was undertaken to determine whether or not splenectomy will bring about any influence upon cerebral excitability in rabbits.

\section{METHOD}

Excitability of the cortex, thalamus, and rhinencephalon of rabbits was

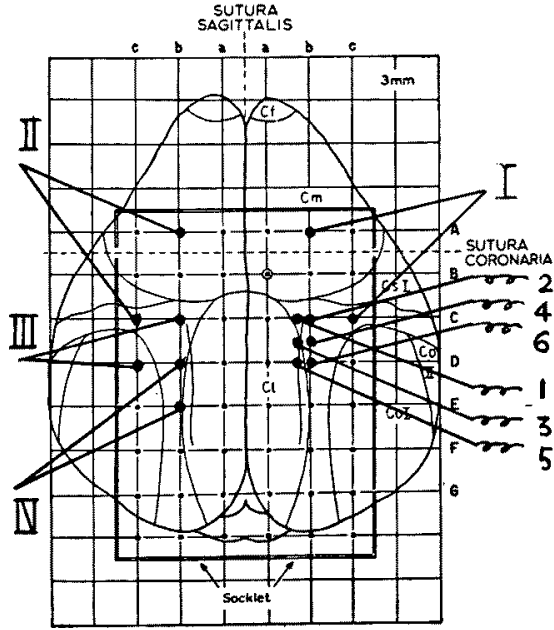

Fig. 1.

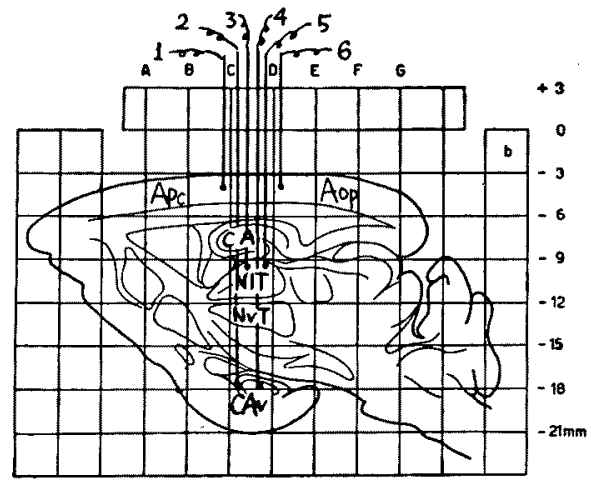

Fig. 2.

水野 隆 


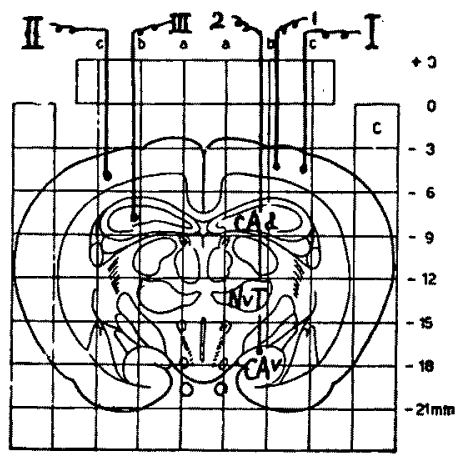

Fig. 3.

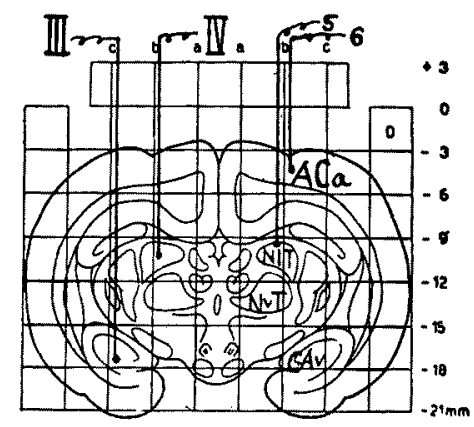

Fig. 4.



Fig. 5.

Figs. 1-5. Location of electrodes for electric stimulation and derivation, according to Gangloff and Monnier. ${ }^{2}$ )

1 and 6 ; electrodes for stimulation of cortex.

2 and 4; electrodes for stimulation of ventral rhinencephalon.

3 and 5; electrodes for stimulation of lateral thalamus.

I; electrode for derivation of activity from right sensorimotorcortex.

II; electrode for derivation of activity from left sensorimotorcortex.

III; electrode for derivation of activity from left rhinencephalon.

IV; electrode for derivation of activity from left thalamus.

Apc: Area praecentralis, Apt: Area postcentralis, Aop: Area optica,

CA: Cornu Ammonis, N1T: Nucleus lateralis thalami, NvT: Nucleus ventralis thalami,

PT: Pulvinar thalami, NoT: Nucleus centralis thalami, ACa: Area calcarina, CAd:

Cornu Ammonis dorsalis, CAv: Cornu Ammonis ventralis.

estimated $^{1)}$ according to the procedure of Gangloff and Monnier ${ }^{2)}$ (cf. Figs. 1-5).

\section{RESULTS AND DISCUSSION}

In the control 10 rabbits, the average thresholds of the cortex, thalamus and ventral rhinencephalon were found to be 6.8 volt, 3.1 volt, and 5.1 volt 
TABLE I. The Influence of Splenectomy on the Threshold in Volt of the Cerebral Excitability in Rabbits

\begin{tabular}{|c|c|c|c|c|}
\hline & No. of rabbits & $\begin{array}{c}\text { Cortical } \\
\text { threshold } \\
\text { in volt }\end{array}$ & $\begin{array}{l}\text { Thalamic } \\
\text { threshold } \\
\text { in volt }\end{array}$ & $\begin{array}{l}\text { Rhinencephalic } \\
\text { threshold } \\
\text { in volt }\end{array}$ \\
\hline $\begin{array}{l}\text { Control } \\
\text { rabbits }\end{array}$ & $\begin{array}{c}1 \\
2 \\
3 \\
4 \\
5 \\
6 \\
7 \\
8 \\
9 \\
10 \\
\text { Average } \\
\pm \text { Standard } \\
\text { deviation }\end{array}$ & $\begin{array}{r}13.0 \\
6.5 \\
2.5 \\
7.0 \\
6.5 \\
5.5 \\
10.0 \\
7.0 \\
6.0 \\
4.5 \\
6.8 \\
\pm 2.9\end{array}$ & $\begin{array}{r}4.0 \\
2.0 \\
1.5 \\
2.5 \\
3.0 \\
3.0 \\
3.5 \\
4.0 \\
4.0 \\
4.0 \\
3.1 \\
\pm 0.2\end{array}$ & $\begin{array}{r}5.0 \\
6.5 \\
6.0 \\
2.5 \\
5.5 \\
4.0 \\
7.0 \\
6.0 \\
4.5 \\
4.0 \\
5.1 \\
\pm 1.3\end{array}$ \\
\hline $\begin{array}{l}\text { Splenecto- } \\
\text { mized } \\
\text { rabbits }\end{array}$ & $\begin{array}{c}11 \\
12 \\
13 \\
14 \\
15 \\
16 \\
17 \\
18 \\
19 \\
\text { Average } \\
\pm \text { Standard } \\
\text { deviation }\end{array}$ & $\begin{array}{r}5.5 \\
7.0 \\
5.0 \\
2.0 \\
9.5 \\
5.5 \\
10.5 \\
2.5 \\
6.0 \\
5.9 \\
\pm 2.8\end{array}$ & $\begin{array}{r}6.0 \\
5.0 \\
5.5 \\
3.5 \\
4.0 \\
4.0 \\
6.0 \\
2.0 \\
3.5 \\
4.3 \\
\pm 1.7\end{array}$ & $\begin{array}{r}2.5 \\
2.5 \\
2.0 \\
3.5 \\
2.0 \\
3.5 \\
4.5 \\
3.0 \\
8.0 \\
3.5 \\
\pm 1.8\end{array}$ \\
\hline
\end{tabular}

respectively (cf. Table I). These values were in a fairly good accordance with those reported by Gangloff and Monnier. ${ }^{21}$

As regards the relationship between the thresholds of the thalamus and those of the ventral rhinencephalon, it was found in the control rabbits that the cases in which thalamic thresholds were lower than the ventral rhinencephalic thresholds were found in 8 cases (Nos. 1-3,5-9) out of the 10 cases examined (cf. Figs. 6 \& 7).

In the case of the splenectomized rabbits, as was shown in Fig. 8, it was worthy to note that the cases in which thalamic thresholds were elevated above those of the ventral rhinencephalon were found in 7 cases (Nos. 11-17) out of the 9 splenectomized rabbits (cf. Figs. $6 \& 8$ ).

This conversion of the relationship between the thalamic thresholds and the ventral rhinencephalic thresholds in the splenectomized rabbits was the result beyond my expectations, but it was actually resulted from 1) a significant increase in the thalamic threshold, and 2) a significant decrease in the ventral rhinencephalic threshold (cf. Table I). 


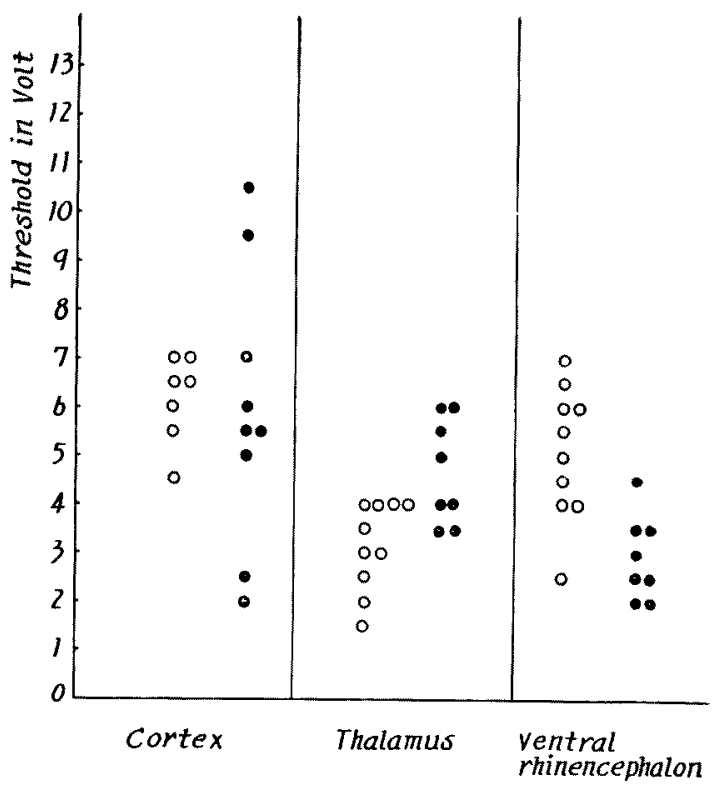

Fig. 6. The excitability thresholds of the cortex, thalamus and ventral rhinencephalon in the control and the splenectomized rabbits. (Open circles indicate the value for the control, and solid circles for the splenectomized rabbits.)

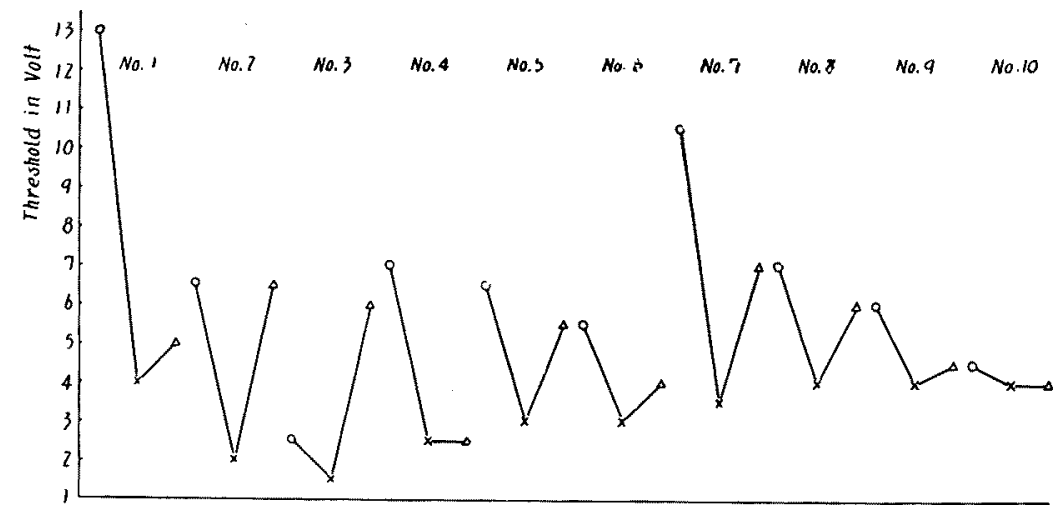

Fig. 7. The thresholds of the cortex, thalamus and ventral rhinencephalon in control rabbits (Nos. 1-10).

(o, indicates the threshold in volt for the cortex; $x$, for the thalamus;

$\Delta$, for the ventral rhinencephalon). 


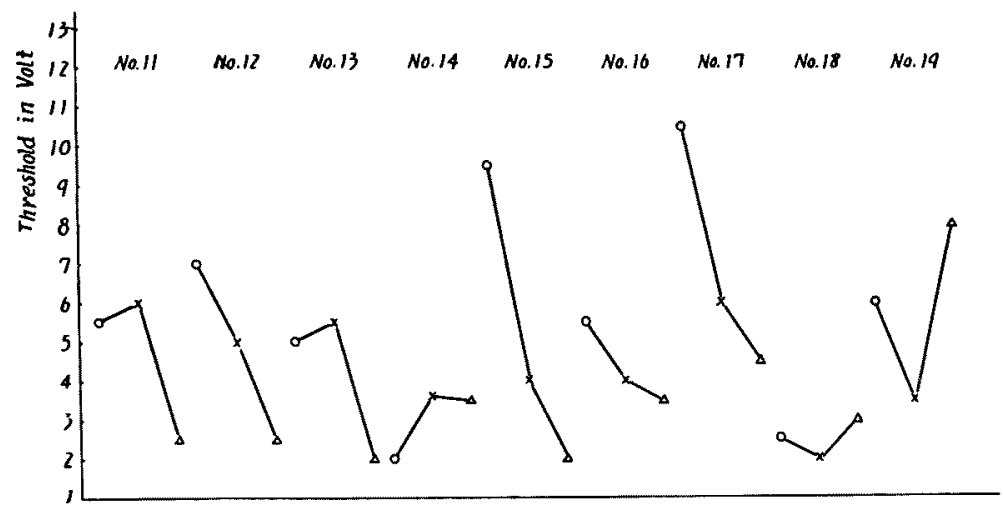

Fig. 8. The thresholds of the cortex, thalamus, and ventral rhinencephalon in the splenectomized rabbits (Nos. 11-19).

( 0 , indicates the threshold in volt for the cortex; $x$, for the thalamus;

$\Delta$, for the ventral rhinencephalon).

\section{CONCLUSIONS}

Splenectomy resulted in a definite alteration in the cerebral excitability of rabbits: - 1) A significant increase in the thalamic threshold, and 2) a significant decrease in the threshold of the ventral rhinencephalon.

\section{References}

1) Mizuno, T., et al., Tohoku J. Exper. Med., 1962, 77, 96.

2) Gangloff, H., \& Monnier, M., EEG \& clin. Neurophysiol., 1957, 9, 43. 